\title{
A Hexagon of Opposition for the Theism/Atheism Debate
}

\author{
Lorenz Demey
}

\section{Introduction}

Keith Burgess-Jackson (forthcoming) has recently revisited Antony Flew's famous essay "The Presumption of Atheism" (Flew 1972). After a thorough conceptual elucidation of the notion of presumption in general, and the notion of (a presumption of) atheism in particular, BurgessJackson goes on to argue that two of Flew's key arguments in favor of a presumption of atheism ultimately fail. The modest goal of the present paper is not to enter into this debate itself however significant it may be from a philosophical, theological, and societal perspective but rather to make some broader methodological remarks. In particular, I want to emphasize the powerful role that well-chosen Aristotelian diagrams can play in organizing and clarifying the debate. I will first describe Burgess-Jackson's own proposal, viz. to make use of a classical square of opposition to represent (the logical structure underlying) the debate between theism and atheism. Next, I will show that this square can naturally be extended to a larger, more complex Aristotelian diagram, viz. a hexagon of opposition. Finally, I will argue that this hexagon has many advantages over the classical square, and is thus a superior representation of the theism/atheism debate.

\section{Burgess-Jackson's square of opposition for the theism/atheism debate}

In line with his view that conceptual clarification is one of the key tasks of philosophy, BurgessJackson (forthcoming) begins his discussion with a detailed analysis of the notions of presumption and atheism. This analysis is carried out using standard philosophical techniques, such as drawing meticulous distinctions between certain categories and charting the logical relations between them, and carefully analyzing how certain words are used in ordinary language (e.g. "to presume" versus "to assume"). In addition to these discursive techniques, another fruitful method consists in visualizing philosophical positions (and their interconnections) by means of various types of diagrams. Throughout his discussion, Burgess- 
Jackson regularly makes use of several (non-Aristotelian) ${ }^{1}$ diagrams and matrices, e.g. to explain his claim that both theism and atheism involve belief as well as nonbelief (BurgessJackson forthcoming, p. 10). A particularly useful type of diagrams is that of the Aristotelian diagrams, which visually represent certain propositions and the Aristotelian relations holding between them (i.e., the relations of contradiction, contrariety, subcontrariety and subalternation). These diagrams have a rich tradition in philosophical research and education in general (Parsons 2017; Demey 2017), and recently they have also been used in the philosophy of religion specifically, e.g. to elucidate the debate between open theism and Molinism on future contingents (Boyd, Belt \& Rhoda 2008; Boyd 2010; Hess 2017; Demey forthcoming). Further examples can be found in Dekker (1993; 2000), Martin Bac (2010) and McCall (2014). Burgess-Jackson suggests in passing that a square of opposition could be useful for clarifying the theism/atheism debate, but he does not provide the actual diagram (BurgessJackson forthcoming, p. 10, Footnote 25). ${ }^{2}$

Burgess-Jackson proposes to view belief as a two-place relationship between a subject and a proposition. Letting $\mathrm{g}$ be the proposition that God exists, the position of theism can then be formalized as Bsg (the subject s believes that God exists), while atheism can best be formalized as Bs $\sim \mathrm{g}$ (the subject s believes that God does not exist). According to this formalization, theism and atheism are contrary to each other, i.e., they cannot be true together (a single subject $\mathrm{s}$ cannot believe, simultaneously, that God exists and that God does not exist, on pain of irrationality), but they can be false together (a subject can rationally fail to believe that God exists as well as that God does not exist; cf. the next section for more discussion). Furthermore, there is a subalternation from theism (Bsg) to non-atheism ( $\sim \mathrm{Bs} \sim \mathrm{g}$ ), which illustrates BurgessJackson's claim that the theist believes certain propositions (viz. g) but — in virtue of being a theist - also does not believe certain other propositions (viz. $\sim \mathrm{g}$ ) (so it would be misleading to characterize the theist as being simply a "believer"). Completely analogously, there is a

\footnotetext{
1 These diagrams are labeled "non-Aristotelian", because they do not represent the Aristotelian relations of contradiction, (sub)contrariety and subalternation holding between certain propositions.

${ }^{2}$ A similar suggestion was already made by Moulder (1971). It should also be pointed out that Burgess-Jackson has fruitfully made use of Aristotelian (and Venn) diagrams in other areas of philosophical enquiry, such as the philosophy of law. In particular, he has used a square of opposition to elucidate the debate between natural law, negative positivism, positive positivism, Hart's soft positivism and Dworkin's so-called "third theory of law" (Burgess-Jackson 1998).
} 
subalternation from atheism $(\mathrm{Bs} \sim \mathrm{g})$ to non-theism ( $\sim \mathrm{Bsg})$, which illustrates Burgess-Jackson's claim that the atheist, too, believes certain propositions (viz. g) but — in virtue of being an atheist - also does not believe certain other propositions (viz. g) (so it would be misleading to characterize the atheist as being simply a "disbeliever").

These considerations show that the four propositions at issue $-\mathrm{Bsg}, \mathrm{Bs} \sim \mathrm{g}, \sim \mathrm{Bsg}$, and $\sim \mathrm{Bs} \sim \mathrm{g}$ -, together with the Aristotelian relations holding between them, give rise to a square of opposition, as shown in Figure 1. This diagram succinctly represents some of the key positions in the theism/atheism debate, their doxastic commitments (which propositions are believed and which ones are not), as well as the Aristotelian relations holding between those commitments. ${ }^{3}$

$<$ Figure 1 to be inserted here $>$

\section{From square of opposition to hexagon of opposition}

Next to theism and atheism, Burgess-Jackson also identifies the position of agnosticism, which is formalized as the conjunction $\sim \mathrm{Bsg} \& \sim \mathrm{Bs} \sim \mathrm{g}$ (the subject $\mathrm{s}$ neither believes that God exists nor that God does not exist). This notion occupies a central role in Burgess-Jackson's analysis: he introduces it right from the beginning, together with the notions of theism and atheism, and he makes crucial use of it in his discussion with Flew, for example when arguing that "a more accurate title for Flew's essay [instead of "The Presumption of Atheism"] would be "The Presumption of Agnosticism."' (Burgess-Jackson forthcoming, p. 11). In light of its central role, it is unfortunate that the notion of agnosticism is not represented at all in the square of opposition (cf. Figure 1). This representational "gap" becomes all the more surprising once we observe the clear connection between agnosticism and the notions that are indeed represented in the square. In particular, agnosticism is formalized as the conjunction of the square's two lower positions, non-theism $(\sim \mathrm{Bsg})$ and non-atheism $(\sim \mathrm{Bs} \sim \mathrm{g})$ - a fact that is explicitly acknowledged by Burgess-Jackson (forthcoming, p. 10, Footnote 25). It thus seems reasonable

\footnotetext{
${ }^{3}$ Some Aristotelian relations from this square have not been discussed in detail. In particular, there is a contradiction relation between Bsg and its negation, $\sim$ Bsg, since these two propositions cannot be true together and cannot be false together. Similarly, there is a contradiction between Bs $\sim$ g and its negation, $\sim$ Bs $\sim$ g. Finally, $\sim$ Bsg and $\sim$ Bs $\sim$ g are subcontrary: these propositions cannot be false together (because their negations, Bsg and Bs $\sim$ g, cannot be true together; cf. supra).
} 
to add the position of agnosticism to the square of opposition, next to the four positions that are already present in it. Furthermore, in order to keep the diagram closed under negation, we will also add the negation of agnosticism. This position of "non-agnosticism" is formalized as Bsg v Bs $\sim g$ (the subject $\mathrm{s}$ believes that God exists or believes that God does not exist), and thus corresponds to the disjunction of the square's two upper positions, i.e., theism (Bsg) and atheism (Bs $\sim \mathrm{g})$.

By adding the conjunction of its two lower positions as well as the disjunction of its two upper positions, Burgess-Jackson's square of opposition has been expanded into a hexagon of opposition, as shown in Figure 2. This Aristotelian diagram contains not only two additional positions, but also several additional Aristotelian relations: (i) agnosticism and non-agnosticism are contradictory to each other, by definition; (ii) there are trivial subalternations from the two disjuncts (Bsg, Bs $\sim$ ) to their disjunction (Bsg $\vee$ Bs $\sim$ g) and from the conjunction ( $\sim$ Bsg \& $\sim \mathrm{Bs} \sim \mathrm{g}$ ) to each of its conjuncts ( $\sim \mathrm{Bsg}, \sim \mathrm{Bs} \sim \mathrm{g}$ ), (iii) agnosticism is contrary to theism as well as to atheism (if a subject is agnostic, then she cannot simultaneously be theistic or atheistic, on purely logical grounds), and (iv) for similar reasons, non-agnosticism is subcontrary to nontheism as well as to non-atheism.

\section{$<$ Figure 2 to be inserted here $>$}

One can show that there are no other (consistent) Boolean combinations of positions present in Burgess-Jackson's square of opposition. Logically speaking, this means that the hexagon of opposition is the Boolean closure of the square. ${ }^{4}$ As a consequence, it exhibits a highly systematic and "symmetric" logical pattern. In particular, each of the three "positive" positions in the hexagon (theism, atheism, agnosticism) is logically equivalent to the conjunction of its two adjacent positions (cf. equivalences $1-3$ below), while each of the three "negative"

\footnotetext{
${ }^{4}$ A highly similar situation occurs with Burgess-Jackson's square in the philosophy of law (cf. Footnote 2). He notes that Hart's soft positivism cannot be represented in the square of opposition, but rather has to be "depicted separately" (Burgess-Jackson 1998, p. 168). Indeed, in order to incorporate the position of soft positivism into the diagram, the square needs to be extended to a hexagon of opposition, by taking its Boolean closure.
} 
positions (non-theism, non-atheism, non-agnosticism) is logically equivalent to the disjunction of its two adjacent positions (cf. equivalences $4-6$ below). ${ }^{5}$

\begin{tabular}{|c|c|c|c|c|c|}
\hline \multirow[t]{2}{*}{ (1) } & theism & $\Leftrightarrow$ & non-atheism & $\&$ & non-agnosticism \\
\hline & Bsg & $\Leftrightarrow$ & $\sim \mathrm{Bs} \sim \mathrm{g}$ & $\&$ & $(B s g \vee v B s \sim g)$ \\
\hline \multirow[t]{2}{*}{ (2) } & atheism & $\Leftrightarrow$ & non-theism & $\&$ & non-agnosticis \\
\hline & $\mathrm{Bs} \sim \mathrm{g}$ & $\Leftrightarrow$ & $\sim \mathrm{Bsg}$ & $\&$ & $(\mathrm{Bsg} \vee \mathrm{Bs} \sim \mathrm{g})$ \\
\hline
\end{tabular}

(3) agnosticism $\Leftrightarrow$ non-theism \& non-atheism $(\sim \mathrm{Bsg} \& \sim \mathrm{Bs} \sim \mathrm{g}) \quad \Leftrightarrow \quad \sim \mathrm{Bsg} \quad \& \quad \sim \mathrm{Bs} \sim \mathrm{g}$
(4) non-theism $\quad \Leftrightarrow \quad$ atheism $\quad \mathrm{v}$ agnosticism

$\sim \mathrm{Bsg} \quad \Leftrightarrow \quad \mathrm{Bs} \sim \mathrm{g} \quad \mathrm{v} \quad(\sim \mathrm{Bsg} \& \sim \mathrm{Bs} \sim \mathrm{g})$

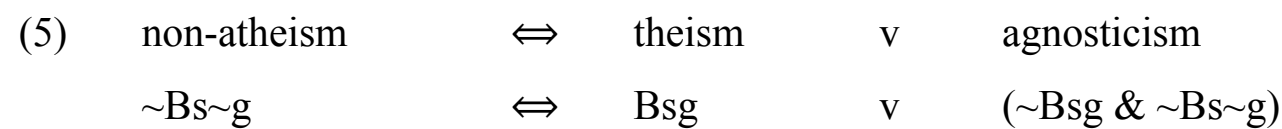

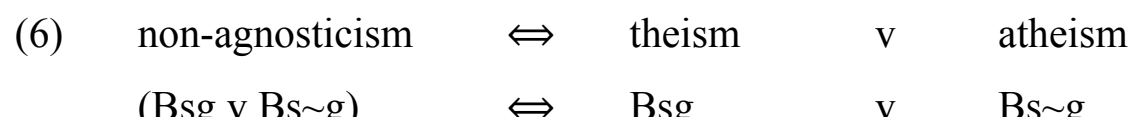

\begin{tabular}{|c|c|}
\hline$(B s g$ v Bs $\sim g)$ & $\Leftrightarrow$ \\
\hline
\end{tabular}

This logical operation (moving from square to hexagon via the Boolean closure) was first studied in the 1950s by the logicians Jacoby (1950), Sesmat (1951) and Blanché $(1953,1966){ }^{6}$ The resulting hexagon is therefore nowadays often called the "Jacoby-Sesmat-Blanché (JSB) hexagon" (Smessaert \& Demey 2014).

\footnotetext{
${ }^{5}$ Note that equivalences 3 and 6 are trivial, because they involve exactly the same proposition on both sides of their $\Leftrightarrow$-sign. Nevertheless, I have explicitly included equivalences 3 and 6 here, in order to emphasize their structural similarity to equivalences $1-2$ and $4-5$, respectively.

${ }^{6}$ Interestingly, these three logicians all worked in a distinctly religious (viz. Catholic) intellectual context. See Jaspers and Seuren (2016) for a detailed historical analysis of the broader cultural background to this observation.
} 


\section{Using the hexagon of opposition to represent the theism/atheism debate}

Since the hexagon of opposition (cf. Figure 2) explicitly contains the positions of agnosticism and non-agnosticism (and their Aristotelian relations to the square's four original positions), it arguably yields a much more helpful representation of (Burgess-Jackson's analysis of) the theism/atheism debate than the original square of opposition. I will now discuss the hexagon's representational advantages in some more detail.

First of all, it should be noted that the JSB hexagon is a proper extension of the square: all positions and relations that are represented by the original square, are still represented by the hexagon. Consequently, all representational advantages of the square (cf. supra) are "inherited" by the hexagon. For example, the hexagon still represents the subalternation from theism (Bsg) to non-atheism ( $\sim \mathrm{Bs} \sim \mathrm{g})$, and thus captures (just like the original square) Burgess-Jackson's claim that the theist believes certain propositions (viz. g) but — in virtue of being a theist also does not believe certain other propositions (viz. $\sim \mathrm{g}$ ) (so, again, it would be misleading to characterize the theist as being simply a "believer").

The additional Aristotelian relations that are present in the JSB hexagon also contribute to its methodological usefulness. For example, the subalternations from agnosticism $(\sim \mathrm{Bsg} \& \sim \mathrm{Bs} \sim \mathrm{g})$ to non-theism ( $\sim \mathrm{Bsg})$ as well as to non-atheism $(\sim \mathrm{Bs} \sim \mathrm{g})$ illustrate the idea that "[a]gnostics are nonbelievers through and through" (Burgess-Jackson forthcoming, p. 10). Furthermore, Burgess-Jackson (forthcoming, p. 10, Footnote 25) says that theism is contrary to atheism as well as to agnosticism. The former contrariety (between theism and atheism) is represented in both the square and the hexagon, but the latter one (between theism and agnosticism) is only represented in the hexagon. (The square of opposition does not represent the position of agnosticism itself, and thus, a fortiori, it cannot represent any Aristotelian relations that this position is involved in.) Similar remarks apply to Burgess-Jackson's remark that atheism is contrary to theism as well as to agnosticism (the latter contrariety is only represented in the hexagon). Finally, Burgess-Jackson also notes that agnosticism is contrary to theism as well as to atheism; both of these contrariety relations are only represented in the hexagon of opposition.

Another methodological advantage of the JSB hexagon concerns its systematic link to tripartitions, which is well-studied in logic (Demey \& Smessaert 2018). Burgess-Jackson (forthcoming, p. 10) begins his discussion by carving out a tripartition of logical space, i.e., a 
division into three positions that are mutually exclusive and jointly exhaustive: theism, atheism, and agnosticism. Each of these three positions occupies a natural place in the triangle of contraries within the JSB hexagon. Indeed, from this perspective, the original square of opposition is clearly seen to be only a partial visualization of the underlying tripartition, which fails to do justice to the systematic and "symmetric" logical pattern (cf. the logical equivalences $1-6$ from the previous section) that this tripartition gives rise to.

The JSB hexagon also sheds new light on Flew's terminology of "positive atheism" and "negative atheism", and their relationship to Burgess-Jackson's own terminology. Flew's notion of positive atheism ( $\mathrm{s}$ believes that God does not exist; Bs $\sim \mathrm{g}$ ) corresponds to BurgessJackson's own notion of atheism. By contrast, Flew's notion of negative atheism (s does not believe that God that exists; $\sim \mathrm{Bsg}$ ) corresponds to the contradictory of theism (which was labeled "non-theism" in Figure 2), and is thus equivalent to the disjunction of atheism (Bs $\sim \mathrm{g})$ and agnosticism ( Bsg $\& \sim \mathrm{Bs} \sim \mathrm{g})$; cf. equivalence 4 from the previous section. There are thus two ways in which one can be a negative atheist: either by being a (positive) atheist, or by being an agnosticist. The subalternation from positive atheism $(\mathrm{Bs} \sim \mathrm{g})$ to negative atheism $(\sim \mathrm{Bsg})$ explains this very terminology: the "positive" notion of atheism entails, but is itself not entailed by, the "negative" notion of atheism.

Finally, the JSB hexagon for theism, atheism and agnosticism also allows us to draw a connection with another part of the literature where JSB hexagons are frequently used, viz. the linguistic discussion about the so-called phenomenon of "NEG-raising" (Bartsch 1973; Horn 1989, 2012; Seuren and Jaspers 2014). When someone utters the words "I don't believe that p", this is typically understood as the stronger claim "I believe that not-p" (cf. Bosanquet 1888, p. 337). In our particular case: when someone utters the proposition corresponding to negative atheism ( $\sim \mathrm{Bsg})$, there is an implication to the effect of positive atheism ( $\mathrm{Bs} \sim \mathrm{g})$. This strengthening phenomenon - which may be either pragmatic or lexical in nature, according to the literature on NEG-raising - is often taken to be the consequence of a "soft" (defeasible) presupposition of excluded middle. In our particular case, the "middle position" that is excluded is exactly the position of agnosticism.

\section{Conclusion}


In this short paper, I have examined Burgess-Jackson's proposal to construct a square of opposition for the theism/atheism debate, and argued that this square can naturally be extended to a hexagon of opposition (viz., a Jacoby-Sesmat-Blanché hexagon). The latter has several representational advantages, and is thus better suited for the crucial philosophical task of conceptual elucidation. It would be naïve to presume that Aristotelian diagrams can, by themselves, lead to a comprehensive solution of debates as intricate as that between theism and atheism. Nevertheless, I hope to have shown in this paper that these diagrams - especially if they are chosen carefully - have an important methodological role to play, by systematically organizing and clarifying the debate.

\section{References}

Bartsch, R. (1973). 'Negative transportation' gibt es nicht. Linguistische Berichte, 27, 1-7.

Blanché, R. (1953). Sur l'opposition des concepts. Theoria, 19, 89-130.

Blanché, R. (1966). Structures intellectuelles. Essai sur l'organisation systématique des concepts. Paris: Vrin.

Bosanquet, B. (1888). Logic. Volume I. Oxford: Clarendon Press.

Boyd, G. A., Belt, T., \& Rhoda, A. (2008). The hexagon of opposition: thinking outside the Aristotelian box. Unpublished manuscript; available online at http://reknew.org/2008/01/thehexagon-essay/ (accessed on 30 October 2017).

Boyd, G.A. (2010). Two ancient (and modern) motivations for ascribing exhaustively definite foreknowledge to God: a historic overview and critical assessment. Religious Studies, 46, 41 59.

Burgess-Jackson, K. (1998). Teaching legal theory with Venn diagrams. Metaphilosophy, 29, 159-177. 
Burgess-Jackson, K. (forthcoming). Rethinking the presumption of atheism. International Journal for Philosophy of Religion. DOI 10.1007/s11153-017-9637-y.

Dekker, E. (1993). Jacobus Arminius and his logic: analysis of a letter. Journal of Theological Studies, 44, 118-142.

Dekker, E. (2000). The theory of divine permission according to Scotus' Ordinatio I 47. Vivarium, 38, 231-242.

Demey, L. (2017). Using syllogistics to teach metalogic. Metaphilosophy, 48, 575-590.

Demey, L. (forthcoming). Aristotelian diagrams in the debate on future contingents. A methodological reflection on Hess's open future square of opposition. Sophia. DOI 10.1007/s11841-017-0632-7.

Demey, L., \& Smessaert, H. (2018). Combinatorial bitstring semantics for arbitrary logical fragments. Journal of Philosophical Logic, 47, 325-363.

Flew, A. (1972). The presumption of atheism. Canadian Journal of Philosophy, 2, 29-46.

Hess, E. (2017). The open future square of opposition: a defense. Sophia, 56, 573-587.

Horn, L. R. (1989). A Natural History of Negation. Chicago: University of Chicago Press.

Horn, L. R. (2012). Histoire d'*O: Lexical Pragmatics and the Geometry of Opposition. In: Béziau, J.-Y., \& Payette, G. (eds.), The Square of Opposition: A General Framework for Cognition. Bern: Peter Lang, pp. 383-416.

Jacoby, P. (1950). A triangle of opposites for types of propositions in Aristotelian logic. New Scholasticism, 24, 32-56.

Jaspers, D., \& Seuren, P. A. M. (2016). The square of opposition in Catholic hands: a chapter in the history of 20th-century logic. Logique et Analyse, 59, 1-35. 
Martin Bac, J. (2010). Perfect Will Theology: Divine Agency in Reformed Scholasticism as Against Suárez, Episcopius, Descartes, and Spinoza. Leiden: Brill.

McCall, T. H. (2014). Was Arminius an (unwitting) determinist? Another look at Arminius's modal logic. Journal of Reformed Theology, 8, 301-309.

Moulder, J. (1971). Logicians and agnostics. Sophia, 10, 1-5.

Parsons, T. (2017). The traditional square of opposition. In: Zalta, E. N. (Ed.), Stanford Encylcopedia of Philosophy, Summer 2017 edition.

Sesmat, A. (1951). Logique II. Les raisonnements. La syllogistique. Paris: Hermann.

Smessaert, H., \& Demey, L. (2014). Logical geometries and information in the square of oppositions. Journal of Logic, Language and Information, 23, 527-565.

Seuren, P. A. M., \& Jaspers, D. (2014). Logico-cognitive structure in the lexicon. Language, 90, 607-643. 


\section{$<$ FIGURES $>$}

$<$ Figure $1>$

(a)

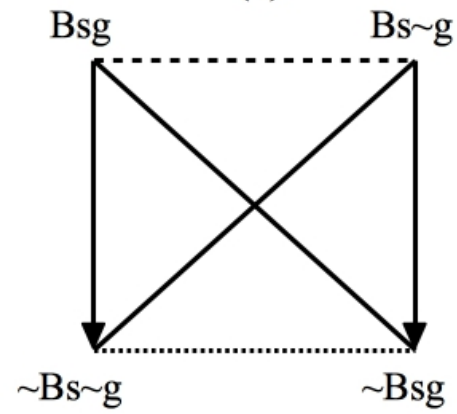

(b)

\section{contradiction \\ contrariety \\ subcontrariety \\ subalternation}

Fig. 1: (a) square of opposition for the theism/atheism debate; (b) visual code for the Aristotelian relations.

$<$ Figure $2>$

(a)

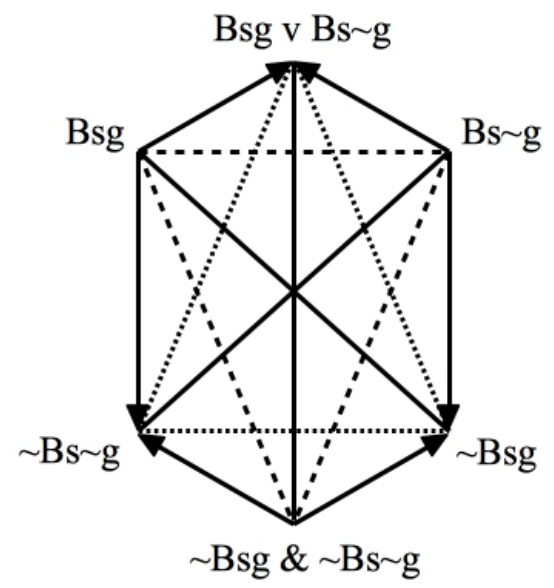

(b)

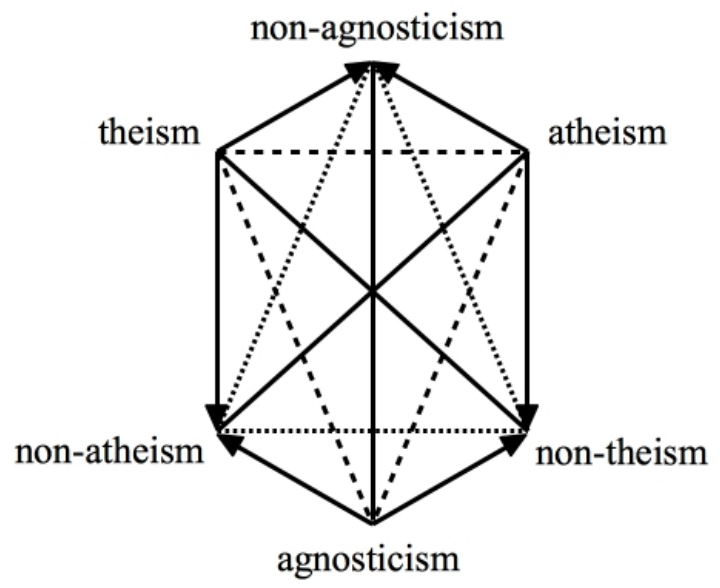

Fig. 2: hexagon of opposition for the theism/atheism debate (in two versions). 